\title{
Epidemiology and types of oral cancer
}

\author{
Rajeh M. Al-Sharif ${ }^{1 *}$, Dalia Y. Batwa ${ }^{2}$, Turki N. Alotaibi ${ }^{3}$, Naif M. Alwadai ${ }^{4}$, \\ Abdullah H. Alsharif ${ }^{5}$, Nedaa A. Azhar ${ }^{6}$, Arjumand A. Moulana ${ }^{7}$, Shoroug M. Alahmadi ${ }^{8}$, \\ Meshal Y. Althobaiti ${ }^{9}$, Duaa F. Bayyumi ${ }^{10}$, Wejdan I. Alzahrani ${ }^{11}$
}

\author{
${ }^{1}$ North Jeddah Specialist Dental Center, King Abdullah Medical Complex, Jeddah, Saudi Arabia \\ ${ }^{2}$ General Dentist, Nees Medical Company, Jeddah, Saudi Arabia \\ ${ }^{3}$ General Dentist, Ministry of Health, Hail, Saudi Arabia \\ ${ }^{4} \mathrm{Al}$ Taneem Primary Healthcare Center, Ministry of Health, Makkah, Saudi Arabia \\ ${ }^{5}$ Al-Ahad Primary Healthcare Center, Ministry of Health, Jazan, Saudi Arabia \\ ${ }^{6}$ General Dentist, Al Noor Specialist Hospital, Makkah, Saudi Arabia \\ ${ }^{7}$ Al Kakiyah Primary Healthcare Center, Ministry of Health, Makkah, Saudi Arabia \\ ${ }^{8}$ General Dentist, Lamasat Al-Noor Clinics Complex, Medina, Saudi Arabia \\ ${ }^{9}$ College of Dentistry, Umm Al-Qura University, Makkah, Saudi Arabia \\ ${ }^{10}$ General Dentist, Moon Smile Clinics, Jeddah, Saudi Arabia \\ ${ }^{11}$ General Dentist, Saudi Hospital, Jeddah, Saudi Arabia
}

Received: 31 December 2021

Accepted: 05 January 2022

\section{*Correspondence:}

Dr. Rajeh M. A. Sharif,

E-mail: dr.rmsh@hotmail.com

Copyright: (c) the author(s), publisher and licensee Medip Academy. This is an open-access article distributed under the terms of the Creative Commons Attribution Non-Commercial License, which permits unrestricted non-commercial use, distribution, and reproduction in any medium, provided the original work is properly cited.

\section{ABSTRACT}

Oral cancer is a subset of head and neck cancer and usually refers to different neoplastic conditions that impact any tissue within the oral cavity. Evidence shows that these malignancies are associated with different complications over the affected patients. The present literature review will discuss the epidemiology and types of oral cancer based on evidence from relevant studies within the literature. Estimates show that oral cancer is a common condition with high prevalence rates globally. However, we have identified several factors across the different relevant investigations, including smoking, alcohol intake, age, socioeconomic status, immunocompromised state, and genetics. This might explain the inconsistent findings regarding the prevalence and mortality rates of the conditions among worldwide studies. Moreover, squamous cells carcinoma is the commonest type of oral cancer. However, other types might also be identified as adenocarcinoma, sarcoma, melanoma, and lymphoma. These lesions can also be found at different places within the mouth cavity, including lips, tongue, and salivary glands. Therefore, healthcare authorities should plan adequate interventional strategies targeting the risk factors to properly control the disease and reduce its burden.

Keywords: Oral cancer, Cancer lip, Cancer tongue, epidemiology, Type, Risk factors

\section{INTRODUCTION}

Recently, the burdens of non-communicable diseases have increased over the affected patients and healthcare settings, significantly impairing these communities' quality of life and socioeconomic characteristics. ${ }^{1,2}$ For example, cardiovascular diseases, chronic respiratory diseases, diabetes, and cancer are the commonest non- communicable diseases across the different communities. ${ }^{3,4}$ In addition, cancer is a serious condition that is highly prevalent in different healthcare settings, with high burdens and alarming mortality rates. ${ }^{5}$

Oral cancer is a subset of head and neck cancer and usually refers to different neoplastic conditions that impact any tissue within the oral cavity. Evidence shows that these 
malignancies are associated with different complications over the affected patients. Moreover, they might have different metastatic activities for different tissues all over the body, increasing their burdens. They can arise within different places in the oral cavity and are mostly found as squamous cell carcinoma. Many risk factors have been associated with the disease, which is essential when studying epidemiology and planning proper interventions. ${ }^{6,7}$ The present literature review will discuss the epidemiology and types of oral cancer based on evidence from relevant studies within the literature.

\section{METHODS}

This literature review is based on an extensive literature search in Medline, Cochrane, and EMBASE databases on which was performed 03 December 2021 using the medical subject headings (MeSH) or a combination of all possible related terms, according to the database. To avoid missing poetential studies, a further manual search for papers was done through Google Scholar, while the reference lists of the initially included papers. Studies discussing epidemiology and types of oral cancer were screened for useful information, with no limitations posed on date, language, age of participants, or publication type.

\section{DISCUSSION}

\section{Prevalence}

Estimates from worldwide investigations indicate increasing trends of oral cancer globally, and the disease progression has been remarkable in the past decades. However, it should be noted that based on the different epidemiological data, the epidemiology of the disease is remarkably inconsistent across the different worldwide populations. ${ }^{8}$ For instance, estimates from Australia show that around 4000 cases/year of head and neck cancer (including lip cancer) are being diagnosed across the country. Among these, it has been reported that around 600 of them are oral cancers. Moreover, evidence shows that the prevalence of cancer in developing countries is high, ranking $10^{\text {th }}$ and $6^{\text {th }}$ among men and women cancers, respectively. Worldwide estimates also indicate that the prevalence of oral cancer might be up to 400000 cases per year. Moreover, the prevalence is highest in Asian populations (including Bangladesh, Pakistan, India, Indonesia, and Sri Lanka), representing around two-thirds of the worldwide cases. ${ }^{9}$ Estimates from these countries also show that oral cancer is the commonest malignancy in their population and can represent around one-fourth of the total malignancies. ${ }^{10}$ In 2018, data from the International Agency for Research on Cancer indicate that the top three countries with the highest prevalence rates of oral cancer were located in Asia and the Pacific region. ${ }^{11}$

\section{Risk factors}

Many risk factors were reported in the literature for developing oral cancer. For instance, it has been shown that smoking and tobacco use are among the most significant risk factors associated with developing the tumor. Previous studies reported that among patients who smoke and do not drink alcohol, the risk of developing oral cancer increases by two times. The relation is also significantly associated with the duration and frequency of alcohol intake. On the other hand, it has been shown that a similar risk was also reported for alcohol drinkers that never smoke. However, it should be noted that this correlation only works for patients that heavily drink alcohol. ${ }^{12}$ Studies also indicate that the risk of developing oral cancer significantly increases by five times from baseline with smokers and alcohol drinkers at the same time. ${ }^{13}$ Other studies also reported that betel quid consumption is usually associated with the development of oral cancer. ${ }^{14,15}$ This has been indicated in a previous systematic review, which reported that a three-fold increase in the risk of oral cancer was significantly associated with betel quid consumption among nonsmokers. ${ }^{14}$ Data from relevant investigations also indicate great benefits from quitting smoking and alcohol consumption. ${ }^{16}$ Previous studies from Saudi Arabia and Yemen also indicated that the risk of oral cancer was significantly associated with using Shamma and Qat. ${ }^{17-19}$ Accordingly, when planning to intervene against oral cancer, healthcare authorities should establish proper campaigns to eliminate these events.

The socioeconomic status was also reported as a significant risk factor for developing oral cancer. In this context, it has been shown that low income and low educational levels are the most significant risk factors associated with developing the disorder. ${ }^{20}$ Moreover, studies also indicate that dietary contents and oral health are also other significant risk factors. On the other hand, it has been shown that obesity is not a significant risk factor for developing oral cancer. However, studies even reported that low body mass index was significantly correlated with developing oral cancer. ${ }^{21}$ In addition, according to some previous studies, being young and having certain genetics might also increase the risk of developing oral cancer. ${ }^{22,23}$ Finally, another risk factor might be a human papillomavirus infection. ${ }^{24,25}$ Previous reports even showed that the risk of developing oral cancer might be increased by 15 times after being infected with human papillomavirus 16 compared to normal patients with no evidence of infection. ${ }^{26}$ Evidence from relevant studies also indicates that reduced exposure to ultraviolet rays might also increase the risk of developing lip cancer, explaining the high rates of lip cancer in Australia. Factors that lead to an immunodeficiency status were also reported (including HIV infections) and other factors such as vitamin A deficiency and Plummer-Vinson syndrome. ${ }^{27,28}$

\section{Mortality and survival rates}

Estimates in 2012 from the International Agency for Research on Cancer (IARC) show that the total death of oral cancer has been estimated to be $1.9 \%$ of all cancer deaths, with an approximate number of 145353 deaths 
from oral cancer this year. Moreover, the mortality rates are not usually associated with the prevalence rates. For instance, it has been reported that the prevalence rates of oral and lip cancers are highest in Bangladesh. However, this country ranks $6^{\text {th }}$ among the highest countries with mortality rates. ${ }^{29}$ Gender is also a significant risk factor. For instance, it has been reported that the mortality rates are usually higher among males than females. ${ }^{30} \mathrm{~A}$ previous study reported that female patients could survive for up to 25 years while male patients could survive for two years only. ${ }^{31}$ Besides, trends of oral cancer mortality show that the prevalence is decreasing among women between 2002 and 2011. However, this has not been the case with oral cancer mortalities among men. ${ }^{32,33}$ In the United States, it has been shown that the prevalence of mortality from oral cancer ranks the $15^{\text {th }}$ and $17^{\text {th }}$ for men and women, respectively. ${ }^{34}$ In contrast, evidence from Europe shows that cancer ranks $7^{\text {th }}$ and $10^{\text {th }}$ for both genders, respectively. ${ }^{35}$ In the same context, oral cancer is the $3^{\text {rd }}$ commonest etiology for death in Slovakia and Hungary. ${ }^{29}$

A previous epidemiological investigation from the Netherlands also demonstrated that the median survival duration of oral cancer was 3.9 years between 1989 and $2006 .{ }^{36}$ Previous studies also demonstrated that mortality from oral cancer is higher among black patients than Pacific islanders, Asians, Alaskan natives, American Indian, and white patients. A $28 \%$ reduction in mortality risk was reported for non-black races with oral cancer. On the other hand, black patients with oral cancer had a $48 \%$ increase in mortality risk than white patients and other races. ${ }^{37}$ It should also be noted that the risk of mortality from lip cancer is higher in developing countries, particularly among females. Moreover, it has been reported that age is a remarkable prognostic factor that should be considered when evaluating the prognosis of these tumors. ${ }^{38}$

\section{Types and sites of oral cancer}

Different types have been identified for oral and mouth cancer. However, the most frequently encountered carcinoma is squamous cell carcinoma. Other types of mouth cancer might also include adenocarcinoma (affecting salivary glands), lymphomas (affecting lymphoid tissues), sarcomas, and melanomas. These tumors affect various issues related to the mouth and oral cavity. In the present section, we will discuss the different places for oral cancer and the epidemiology of this neoplasm according to data from relevant studies in the literature.

\section{Tongue cancer}

Evidence from different relevant epidemiological studies shows that oral tongue carcinoma is one of the most prevalent oral cancers. However, the epidemiology, prognosis, and behavior of the condition are remarkably variable. $^{39}$ It should be noted that tongue carcinoma usually refers to carcinoma affecting the base of the tongue (pharyngeal tongue) and unknown tongue. It has been estimated that tongue carcinoma is the most typical malignant oral lesion, with a high prevalence rate that ranges between $20-45 \% .{ }^{31,40,41}$ The left and right palatal borders have the following prevalence rates reported in 61$39 \%$ cases. This might be associated with smoking patterns, a significant risk factor for developing this type of cancer. Moreover, it has been shown that the prevalence of tongue cancer is highest in India among both genders.

In contrast, evidence from Australia shows that the prevalence of tongue cancer in their female population was the highest compared to other worldwide communities (the incidence was estimated to be 5.2 per 100,0000 population). Studies also indicate that the prevalence of tongue cancer is usually higher among females of specific populations, including Japanese ancestors, ethnic Chineses, and Hawaiians. ${ }^{42}$ In Europe, the prevalence is also high. For instance, there have been high tongue cancer rates in Switzerland, Portugal, France, and Slovakia.

\section{Lip and mouth cancer}

Estimates show that the highest prevalence of mouth cancer rates in both genders are found in India. Moreover, it has been shown that the second prevalence rate of the condition has been reported in a local region in France among males. It has been furtherly shown that the condition is also prevalent in different European countries, including Spain, Portugal, Slovakia, and Germany. The prevalence of mouth cancer is also high in South American countries, especially Brazil. It has been furtherly shown that among Australian women, the prevalence of mouth cancer was higher in indigenous than non-indigenous populations. ${ }^{42,43}$ Studies also show that cancer mouth is the $1^{\text {st }}$ and $4^{\text {th }}$ type of oral cancer among males and females in India, respectively. Evidence from different epidemiological studies indicates increasing trends of mouth cancer in different regions globally because of the increased exposure to different relevant risk factors. Studies also indicate that the prevalence of cancer is higher on the lower than upper lips. Among the different types of squamous cell carcinomas, it has been estimated that both of these types usually represent around $20-30 \%$ of them. ${ }^{44}$ In the United States, it has been reported that the incidence is 4 per 100000 population among white males. However, it has also been noted that the incidence is significantly associated with age. ${ }^{45}$ In the different global settings, Portugal, Australia, and Spain had the highest prevalence rates of lip cancer. Moreover, the prevalence of the condition among females was highest in Australia. Higher rates were also reported in Brazil and Thailand. ${ }^{42}$ There is also a significant correlation between the incidence of lip carcinoma and age. ${ }^{39}$ Estimates also indicate that squamous cell carcinoma of the lower lip is significantly higher among white than black males in the United States. ${ }^{46}$ However, recent estimates show that the trends of these events are dramatically decreasing in these populations. Higher rates of cancer lip were also reported among Hispanic groups of both genders. ${ }^{47-50}$ 


\section{CONCLUSION}

Estimates show that oral cancer is a common condition with high prevalence rates globally. However, we have identified several factors across the different relevant investigations, including smoking, alcohol intake, age, socioeconomic status, immunocompromised state, and genetics. This might explain the inconsistent findings regarding the prevalence and mortality rates of the conditions among worldwide studies. Moreover, squamous cells carcinoma is the commonest type of oral cancer. However, other types might also be identified as adenocarcinoma, sarcoma, melanoma, and lymphoma. These lesions can also be found at different places within the mouth cavity, including lips, tongue, and salivary glands. Therefore, healthcare authorities should plan adequate interventional strategies targeting the risk factors to properly control the disease and reduce its burden.

Funding: No funding sources

Conflict of interest: None declared

Ethical approval: Not required

\section{REFERENCES}

1. Zinat Motlagh SF, Chaman R, Ghafari SR, Parisay Z, Golabi MR, Eslami AA, Babouei A. Knowledge, Treatment, Control, and Risk Factors for Hypertension among Adults in Southern Iran. Int $\mathbf{J}$ Hypertens. 2015;897070.

2. Boutayeb A. The Burden of Communicable and NonCommunicable Diseases in Developing Countries. Handbook of Disease Burdens and Quality of Life Measures. 2010;531-46.

3. Kim HC, Oh SM. Noncommunicable diseases: current status of major modifiable risk factors in Korea. J Prevent Med Public Health. 2013;46(4):16572.

4. Khang YH. Burden of noncommunicable diseases and national strategies to control them in Korea. J Prevent Med Public Health. 2013;46(4):155-64.

5. Taghibakhsh M, Farhadi S, Babaee A, Sheikhi M. The Effect of Hookah Use on Buccal Mucosa: Evaluation of Repair Index. Asian Pacific J Cancer Prev. 2019;20(4):1109-12.

6. Al-Jaber A, Al-Nasser L, El-Metwally A. Epidemiology of oral cancer in Arab countries. Saudi Med J. 2016;37(3):249-55.

7. Shrestha AD, Vedsted P, Kallestrup P, Neupane D. Prevalence and incidence of oral cancer in low- and middle-income countries: A scoping review. Eur $\mathbf{J}$ Cancer Care. 2020;29(2):e13207.

8. Jeihooni AK, Dindarloo SF, Harsini PA. Effectiveness of Health Belief Model on Oral Cancer Prevention in Smoker Men. J Cancer Educ. 2019;34(5):920-7.

9. Montero PH, Patel SG. Cancer of the oral cavity. Surg Oncol Clin North Am. 2015;24(3):491-508.

10. Abati S, Bramati C, Bondi S, Lissoni A, Trimarchi M. Oral Cancer and Precancer: A Narrative Review on the Relevance of Early Diagnosis. Int J Env Res Public Health. 2020;17(24).

11. Hung LC, Kung PT, Lung CH, Tsai MH, Liu SA, Chiu LT, et al. Assessment of the Risk of Oral Cancer Incidence in A High-Risk Population and Establishment of A Predictive Model for Oral Cancer Incidence Using A Population-Based Cohort in Taiwan. Int $\mathbf{J}$ Environ Res Public Health. 2020;17(2):665.

12. Hashibe M, Brennan P, Benhamou S, Castellsague X, Chen C, Curado MP, et al. Alcohol drinking in never users of tobacco, cigarette smoking in never drinkers, and the risk of head and neck cancer: pooled analysis in the International Head and Neck Cancer Epidemiology Consortium. J Natl Cancer Inst. 2007;99(10):777-89.

13. Hashibe M, Brennan P, Chuang SC, Boccia S, Castellsague $\mathrm{X}$, Chen $\mathrm{C}$, et al. Interaction between tobacco and alcohol use and the risk of head and neck cancer: pooled analysis in the International Head and Neck Cancer Epidemiology Consortium. Cancer Epidemiol Biomarkers Prev. 2009;18(2):541-50.

14. Gupta B, Johnson NW. Systematic review and metaanalysis of association of smokeless tobacco and of betel quid without tobacco with incidence of oral cancer in South Asia and the Pacific. PloS One. 2014;9(11):e113385.

15. Siddiqi K, Gupta PC, Prasad VM, Croucher R, Sheikh A. Smokeless tobacco use by south Asians. Lancet Global Health. 2013;1(2):71.

16. Marron M, Boffetta P, Zhang ZF, Zaridze D, Wünsch-Filho V, Winn DM, et al. Cessation of alcohol drinking, tobacco smoking and the reversal of head and neck cancer risk. Int $\mathbf{J}$ Epidemiol. 2010;39(1):182-96.

17. Sawair FA, Al-Mutwakel A, Al-Eryani K, Al-Surhy A, Maruyama S, Cheng J, Al-Sharabi A, Saku T. High relative frequency of oral squamous cell carcinoma in Yemen: qat and tobacco chewing as its aetiological background. Int J Environ Health Res. 2007;17(3):185-95.

18. Al-Ghamdi SA, Malatani T, Kameswaran M, Khurana P. Head and neck cancer in a referral center in Asir region. Ann Saudi Med. 1994;14(5):383-6.

19. Ibrahim EM, Satti MB, Al Idrissi HY, Higazi MM, Magbool GM, Al Quorain A. Oral cancer in Saudi Arabia: the role of alqat and alshammah. Cancer Detect Prev. 1986;9(3-4):215-8.

20. Conway DI, Brenner DR, McMahon AD, Macpherson LM, Agudo A, Ahrens W, et al. Estimating and explaining the effect of education and income on head and neck cancer risk: INHANCE consortium pooled analysis of 31 case-control studies from 27 countries. Int J Cancer. 2015;136(5):112539.

21. Gaudet MM, Olshan AF, Chuang SC, Berthiller J, Zhang ZF, Lissowska J, et al. Body mass index and risk of head and neck cancer in a pooled analysis of case-control studies in the International Head and 
Neck Cancer Epidemiology (INHANCE) Consortium. Int J Epidemiol. 2010;39(4):1091-102.

22. Winn DM, Lee YC, Hashibe M, Boffetta P. The INHANCE consortium: toward a better understanding of the causes and mechanisms of head and neck cancer. Oral Dis. 2015;21(6):685-93.

23. Toporcov TN, Znaor A, Zhang ZF, Yu GP, Winn DM, Wei Q, et al. Risk factors for head and neck cancer in young adults: a pooled analysis in the INHANCE consortium. Int $\mathrm{J}$ Epidemiol. 2015;44(1):169-85.

24. Conway DI, Robertson C, Gray H, Young L, McDaid LM, Winter AJ, et al. Human Papilloma Virus (HPV) Oral Prevalence in Scotland (HOPSCOTCH): A Feasibility Study in Dental Settings. PLoS One. 2016;11(11):e0165847.

25. Gillison ML, Chaturvedi AK, Anderson WF, Fakhry C. Epidemiology of human papillomavirus-positive head and neck squamous cell carcinoma. J Clin Oncol. 2015;33(29):3235.

26. D'Souza G, Kreimer AR, Viscidi R, Pawlita M, Fakhry C, Koch WM, Westra WH, Gillison ML. Case-control study of human papillomavirus and oropharyngeal cancer. $\mathrm{N}$ Engl J Med. 2007;356(19):1944-56.

27. Conway DI, Purkayastha M, Chestnutt IG. The changing epidemiology of oral cancer: definitions, trends, and risk factors. Br Dent J. 2018;225(9):86773.

28. García-Martín JM, Varela-Centelles P, González M, Seoane-Romero JM, Seoane J, García-Pola MJ. Epidemiology of Oral Cancer. In: Panta P, ed. Oral Cancer Detection: Novel Strategies and Clinical Impact. Cham: Springer International Publishing. 2019;81-93.

29. Ferlay J, Soerjomataram I, Dikshit R, Eser S, Mathers C, Rebelo M, Parkin DM, Forman D, Bray F. Cancer incidence and mortality worldwide: sources, methods and major patterns in GLOBOCAN 2012. Int J Cancer. 2015;136(5):359-86.

30. Liu F, Chen F, Huang J, Yan L, Liu F, Wu J, Qiu Y, Zheng X, Zhang R, Lin L, He B. Prospective study on factors affecting the prognosis of oral cancer in a Chinese population. Oncotarget. 2017;8(3):4352-9.

31. Osazuwa-Peters N, Massa ST, Christopher KM, Walker RJ, Varvares MA. Race and sex disparities in long-term survival of oral and oropharyngeal cancer in the United States. J Cancer Res Clin Oncol. 2016;142(2):521-8.

32. Noone AM, Cronin KA, Altekruse SF, Howlader N, Lewis DR, Petkov VI, Penberthy L. Cancer Incidence and Survival Trends by Subtype Using Data from the Surveillance Epidemiology and End Results Program, 1992-2013. Cancer Epidemiol Biomarkers Prev. 2017;26(4):632-41.

33. Jemal A, Ward E, Thun M. Declining death rates reflect progress against cancer. PloS One. 2010;5(3):e9584.

34. Howe HL, Wu X, Ries LA, Cokkinides V, Ahmed F, Jemal A, et al. Annual report to the nation on the status of cancer, 1975-2003, featuring cancer among U.S. Hispanic/Latino populations. Cancer. 2006;107(8):1711-42.

35. Ferlay J, Steliarova-Foucher E, Lortet-Tieulent J. Cancer incidence and mortality patterns in Europe: estimates for 40 countries in 2012. Eur J Cancer. 2013;49(6):1374-403.

36. Van Monsjou H, Schaapveld M, Hamming-Vrieze O, De Boer J, Van Den Brekel M, Balm A. Causespecific excess mortality in patients treated for cancer of the oral cavity and oropharynx: a population-based study. Oral Oncol. 2016;52:37-44.

37. Emerson MA, Banegas MP, Chawla N. Disparities in prostate, lung, breast, and colorectal cancer survival and comorbidity status among urban American Indians and Alaskan natives. Cancer Res. 2017;77(23):6770-6.

38. Olarte LS, Megwalu UC. The impact of demographic and socioeconomic factors on major salivary gland cancer survival. Otolaryngol Head Neck Surg. 2014;150(6):991-8.

39. Domínguez-Gordillo A, Esparza-Gómez G, GarcíaJiménez B, Cerero-Lapiedra R, Casado-Gómez I, Romero-Lastra P, Warnakulasuriya S. The pattern of lip cancer occurrence over the 1990-2011 period in public hospitals in Madrid, Spain. J Oral Pathol Med. 2016;45(3):202-10.

40. Maleki D, Ghojazadeh M, Mahmoudi SS, Mahmoudi SM, Pournaghi-Azar F, Torab A, Piri R, AzamiAghdash S, Naghavi-Behzad M. Epidemiology of Oral Cancer in Iran: a Systematic Review. Asian Pac J Cancer Prev. 2015;16(13):5427-32.

41. Oliveira MLC, Wagner VP, Sant'ana M, Carrard VC, Hugo FN, Martins MD. A 10-year analysis of the oral squamous cell carcinoma profile in patients from public health centers in Uruguay. Braz Oral Res. 2015;29:1-8.

42. Bray F, Ferlay J, Laversanne M, Brewster DH, Gombe Mbalawa C, Kohler B, et al. Cancer Incidence in Five Continents: Inclusion criteria, highlights from Volume $\mathrm{X}$ and the global status of cancer registration. Int J Cancer. 2015;137(9):206071.

43. El-Qushayri AE, Dahy A, Reda A, Mahmoud MA, Mageed SA, Kamel AMA, Ghozy S. A closer look at the high burden of psychiatric disorders among healthcare workers in Egypt during the COVID-19 pandemic. Epidemiol Health. 2021;43:2021045.

44. Marx RE, Stern D. Oral and maxillofacial pathology: a rationale for diagnosis and treatment. Quintessence Publishing Company Hanover Park. 2012.

45. Siponen M, Neville BW, Damm DD, Allen CM. Multifocal lateral periodontal cysts: a report of 4 cases and review of the literature. Oral Surg Oral Med Oral Pathol Oral Radiol Endodontol. 2011;111(2):225-33.

46. Khammissa R, Meer S, Lemmer J, Feller L. Oral squamous cell carcinoma in a South African sample: Race/ethnicity, age, gender, and degree of 
histopathological differentiation. J Cancer Res Therap. 2014;10(4):908.

47. Dibas M, Doheim MF, Ghozy S, Ros MH, El-Helw GO, Reda A. Incidence and survival rates and trends of skull Base chondrosarcoma: A Population-Based study. Clin Neurol Neurosurg. 2020;198:106153.

48. Son PT, Reda A, Viet DC. Exchange transfusion in the management of critical pertussis in young infants: a case series. Vox Sang. 2021;116(9):976-82.

49. Nguyen TM, Huan VT, Reda A. Clinical features and outcomes of neonatal dengue at the Children's Hospital 1, Ho Chi Minh, Vietnam. J Clin Virol. 2021;138:104758.
50. Thieu H, Bach Dat B, Nam NH, Reda A, Duc NT, Alshareef A, Nguyen JG, Ngoc NM, Tien Huy N. Antibiotic resistance of Helicobacter pylori infection in a children's hospital in Vietnam: prevalence and associated factors. Minerva Med. 2020;111(5):498501.

Cite this article as: Al-Sharif RM, Batwa DY, Alotaibi TN, Alwadai NM, Alsharif AH, Azhar NA, et al. Epidemiology and types of oral cancer. Int $\mathbf{J}$ Community Med Public Health 2022;9:1017-22. 